\title{
Association of $P 73$ polymorphisms with susceptibilities of cervical carcinoma: a meta-analysis
}

\author{
Xianghua Liang ${ }^{1}$, Bingxiang Chen ${ }^{1}$ and Jianxin Zhong ${ }^{2}$ \\ ${ }^{1}$ Department of Gynecology and Obstetrics, Qidong People's Hospital, Jiangsu, China \\ ${ }^{2}$ Department of Gynecology and Obstetrics, Affiliated Hospital of Nantong University, Jiangsu, China \\ Correspondence to: Xianghua Liang, email: liangxianghua@aliyun.com
}

Keywords: P73 gene, cervical cancer, meta analysis

Received: March 31, $2017 \quad$ Accepted: May 09, $2017 \quad$ Published: May 24, 2017

Copyright: Liang et al. This is an open-access article distributed under the terms of the Creative Commons Attribution License 3.0 (CC BY 3.0), which permits unrestricted use, distribution, and reproduction in any medium, provided the original author and source are credited.

\section{ABSTRACT}

Objective: The relation between $P 73$ gene polymorphism and cervical cancer has not been determined. At present, we utilized a meta-analysis method to elucidate the association between $P 73$ and cervical cancer.

Results: The present study included 635 patients with cervical cancer and 998 cancer-free control subjects. Using meta-analysis, we found a significant association of P73 genetic polymorphism with cervical cancer in a recessive model [OR $=0.91$, 95\% CI: 0.84-0.98; $P=0.02$.]. However, this association was not find in a dominant model [OR $=0.76,95 \% \mathrm{CI}(0.45-1.27) ; P=0.29]$, in a co-dominant model [OR $=1.01$; 95\% CI: 0.98-1.04, $P=0.56]$ or in an allelic model [OR $=0.97,95 \%$ CI: $0.93-1.00$; $P=0.09]$.

Materials and Methods: To further evaluate the relation between the P73 gene polymorphism and cervical cancer, we selected 5 case-control studies related to $P 73$ gene polymorphism and cervical cancer by searching CNKI, VIP, WanFang, PubMed and EMbase database. We utilized $Q$-test and $\mathrm{I}^{2}$ test to test the heterogeneity between each study. The fixed effects model was utilized to calculate the odds ratio (OR) and its $95 \%$ confidence interval.

Conclusions: Our results suggest that $P 73$ gene polymorphism was associated with the risk of cervical cancer. However, our conclusion still requires large sample size of case-control studies or cohort studies to further confirm this result.

\section{INTRODUCTION}

Cervical cancer is a common gynecological malignancy with high mortality [1], which is a serious threat to women's health and life [2]. The current evidences suggest that the occurrence and development of cervical cancer is associated with activation of oncogenes [3-4]. Recently, P73 gene is identified a candidate gene of tumor suppressor and plays an important role in the development of many tumors [5-6]. A number of studies have shown that $P 73$ gene polymorphisms are associated with the risk for cervical cancer, but the results are not conclusive. Jha et al. found P73 polymorphism was associated with the risk of cervical cancer in a Japanese population [7]. However, the subsequent studies performed in Caucasian [8] and in China [9] did not shown association of P73 polymorphism with cervical cancer. This inconsistency may result from the small sample size in each study. Therefore, we collected almost all published case-control studies to perform a meta-analysis to clarify the relation between $P 73$ gene polymorphism and cervical cancer.

\section{RESULTS}

Study identification

As shown in Figure 1, 101 literatures including 88 English literatures and 13 Chinese literatures were reviewed preliminarily. 89 literatures were excluded 
because of duplicate publication and nonclinical-based data. 7 studies were further excluded because of no control subjects. Therefore, a total of 5 literatures [7-11] were included in the final analysis, with a total of 635 patients with cervical cancer and 998 cancer-free control subjects. The characteristics of included studies were shown in Table 1.

\section{Quantitative synthesis}

The result of meta-analysis of studies on the correlation between cervical cancer and P73 gene polymorphism in 5 case-control studies as shown in Figure 2 which include the number of case and control groups, weight, OR value, and $95 \% \mathrm{CI}$. The heterogeneity

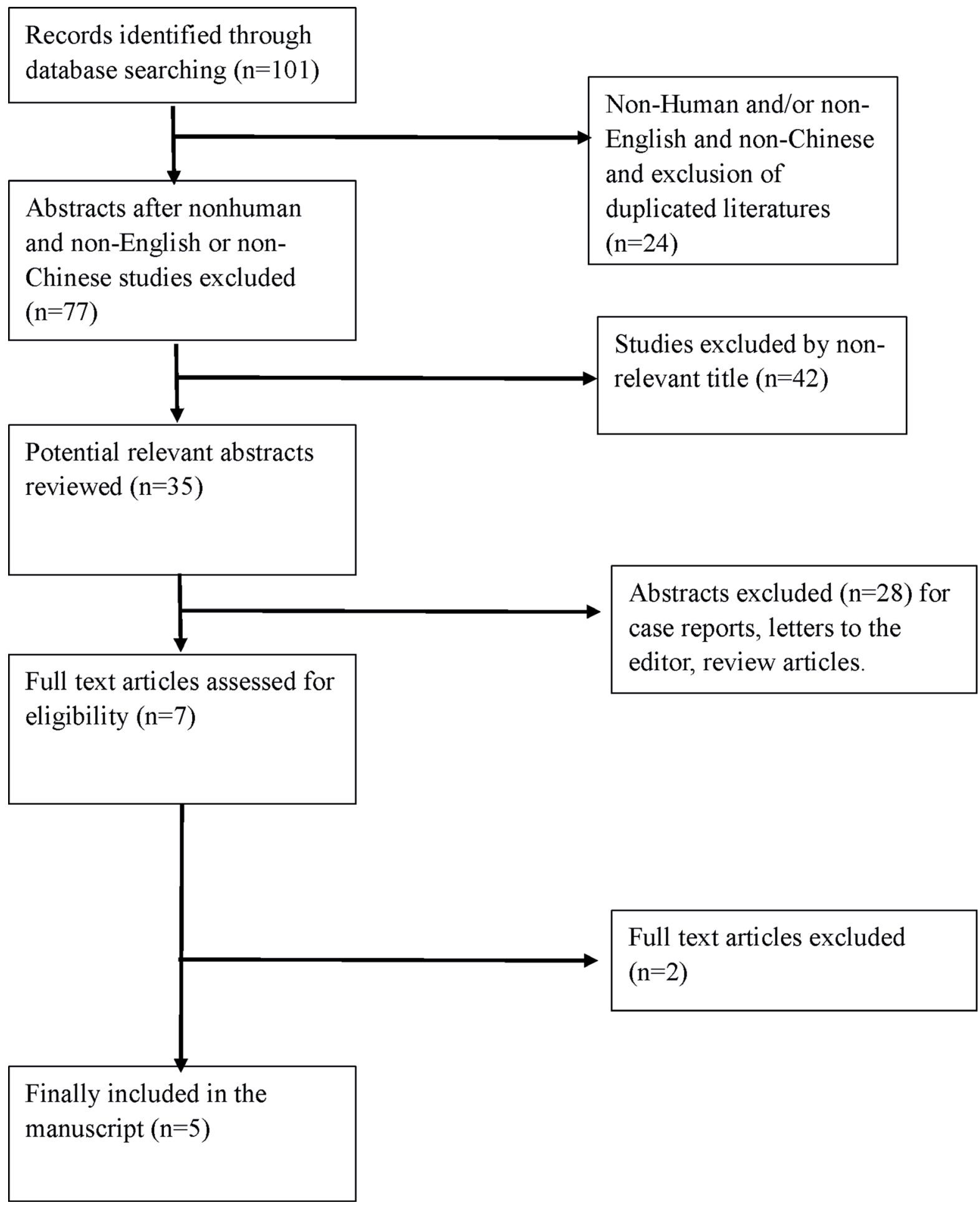

Figure 1: Flow diagram of the literature search and study selection. 
Table 1: Characteristics of included studies

\begin{tabular}{|c|c|c|c|c|c|c|c|}
\hline \multirow{2}{*}{ Authors } & \multirow{2}{*}{ Publication year } & \multirow{2}{*}{ Country } & \multirow{2}{*}{ Ethnicity } & \multicolumn{3}{|c|}{ Genotype (case/control) } & \multirow{2}{*}{$\frac{\text { HWE }}{\text { Yes }}$} \\
\hline & & & & GC/GC & GC/AT & AT/AT & \\
\hline Craveiro et al. & 2012 & Portugal & Caucasus & $95 / 119$ & $38 / 48$ & $8 / 9$ & Yes \\
\hline Jha et al. & 2012 & India & Asian & $71 / 77$ & $28 / 19$ & $2 / 4$ & Yes \\
\hline Niwa et al. & 2004 & Japan & Asian & $57 / 270$ & $52 / 150$ & $3 / 22$ & Yes \\
\hline Zheng et al. & 2008 & China & Asian & $71 / 77$ & $28 / 19$ & $2 / 4$ & Yes \\
\hline Feng et al. & 2017 & China & Asian & $103 / 114$ & $67 / 55$ & $10 / 11$ & Yes \\
\hline
\end{tabular}

test of the various studies did not shown heterogeneous results. Therefore, we used the fixed effects model in the analysis. Overall, the association of P73 with risk of cervical cancer was observed in a recessive model $[\mathrm{OR}=0.91,95 \% \mathrm{CI}: 0.84-0.98, P=0.02$.$] . However, this$ association was not find in a dominant model [OR $=0.76$, 95\% CI (0.45-1.27); $P=0.29]$, in a co-dominant model [OR $=1.01 ; 95 \% \mathrm{CI}: 0.98-1.04, P=0.56]$ or in an allelic model $[\mathrm{OR}=0.97,95 \% \mathrm{CI}: 0.93-1.00 ; P=0.09]$.

\section{Publication bias analysis}

We utilized the RevMan 5.0 software to analyze the publication bias. The funnel plot (Figure 3) shows that the points are evenly distributed and symmetrical, and most of the points are within the $95 \%$ confidence interval, the shape of funnel plot shows no obvious asymmetry. It indicates that there is no publication bias in the present study, and the result is credible.

\section{DISCUSSION}

In the present study, we performed a meta-analysis to evaluate the association of $P 73$ polymorphism with cervical cancer. We find a significant association of $p 73$ gene polymorphism with cervical cancer in a recessive model but not in a dominant, a co-dominant, or an allelic model. This study clarified the association between $P 73$ polymorphism and cervical cancer.

The $P 73$ gene is located at the 1 p36 position on the human chromosome, and the $\mathrm{P} 73$ protein activates transcription of a number of P53-responsive genes to participate in cell cycle regulation, DNA repair and apoptosis, and in the same way as P53 by inducing apoptosis or G1 phase of cell arrest to inhibit cell proliferation [12-16]. Previously, several studies related to the relation between $P 73$ and cervical cancer risk has been reported, however, the results were inclusive. In a Japanese population, GC /AT genotype and AT/AT genotype were associated with the occurrence of cervical cancer [7]. A study of white women in Portugal reported that GC / AT genotype was associated with low age at menarche [8]. However, a recent study of Caucasian showed that $P 73$ gene GC / AT polymorphism was associated with cervical intraepithelial neoplasia (HSIL) and was not associated with cervical cancer [9]. Also, a recent study including Uygur population indicated that $P 73$ gene GC/AT polymorphism was not associated with cervical cancer [11]. This inconsistency may result from the small sample size and the different experimental methods. The present study has shown that $p 73$ gene polymorphism was associated with the susceptibility of cervical cancer. However, there is still a need for further research and screening of etiological relations between the functional polymorphism loci of the $\mathrm{p} 73$ gene and the susceptibility of cervical cancer.

Several limitations should be considered when interpreting these results. Firstly, all literatures involved in our study are of different languages. Secondly, the different research methods may increase the heterogeneity of these studies. Finally, a small sample of some included case-control studies may reduce the test power. To some extent, it reduced the reliability and comprehensiveness of the results of this systemic evaluation.

In conclusion, the present study suggested that there is an association between P73 gene polymorphism and cervical cancer.

\section{MATERIALS AND METHODS}

\section{Literatures collection and screening}

To identify all the articles that explored the association of $P 73$ polymorphisms with cervical cancer risk, we conducted a computerized literature search of MEDLINE, EMBase, Chinese Biomedical Literature Database (VIP), Chinese CNKI, and Wanfang database using the terms "cervical cancer (Mesh)," "P73", "gene polymorphism," or "SNP" without any restriction on language or publication year. By means of online retrieval and literature review, references obtained using the abovementioned databases were reviewed again to ensure that no relevant studies are missed. 
A

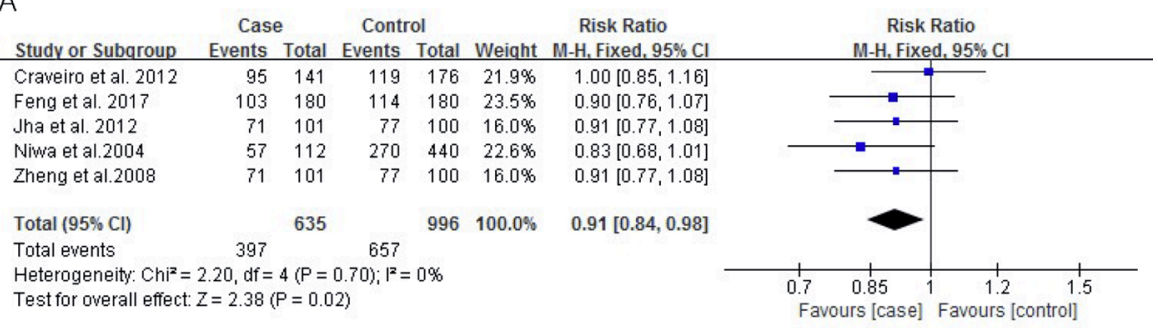

B

\begin{tabular}{|c|c|c|c|c|c|c|c|c|c|c|c|}
\hline Study or Subaroup & $\begin{array}{c}\text { Case } \\
\text { Events }\end{array}$ & Total & $\begin{array}{c}\text { Contr } \\
\text { Events }\end{array}$ & & Weiaht & $\begin{array}{l}\text { Odds Ratio } \\
\text { M-H, Fixed, 95\% Cl }\end{array}$ & & $\begin{array}{r}\text { Odds } \\
\text { M-H, Fixe }\end{array}$ & $\begin{array}{l}\text { Ratio } \\
\text { ed, } 95 \% \mathrm{Cl}\end{array}$ & & \\
\hline Craveiro et al. 2012 & 8 & 141 & 9 & 176 & $21.9 \%$ & $1.12[0.42,2.97]$ & & & & & \\
\hline Feng et al. 2017 & 10 & 180 & 11 & 180 & $30.1 \%$ & $0.90[0.37,2.18]$ & & & & & \\
\hline Jha et al. 2012 & 2 & 101 & 4 & 100 & $11.4 \%$ & $0.48[0.09,2.71]$ & & 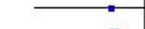 & & & \\
\hline Niwa et al. 2004 & 3 & 112 & 22 & 442 & $25.1 \%$ & $0.53[0.15,1.79]$ & & $=$ & & & \\
\hline Zheng et al. 2008 & 2 & 101 & 4 & 100 & $11.4 \%$ & $0.48[0.09,2.71]$ & & & & & \\
\hline Total $(95 \% \mathrm{Cl})$ & & 635 & & 998 & $100.0 \%$ & $0.76[0.45,1.27]$ & & & & & \\
\hline Total events & 25 & & 50 & & & & & & & & \\
\hline $\begin{array}{l}\text { Heterogeneity: } \mathrm{Chi}^{2} \\
\text { Test for overall effec }\end{array}$ & $\begin{array}{l}1.61, d f= \\
z=1.05(F\end{array}$ & $\begin{array}{l}4(P=0 \\
=0.2\end{array}$ & $\begin{array}{l}\text { 0.81); } F^{2}= \\
\text { 9) }\end{array}$ & & & & 0.01 & $\begin{array}{c}0.1 \\
\text { Favours [case] }\end{array}$ & ${ }^{1}$ Favours & $\begin{array}{l}10 \\
\text { [control] }\end{array}$ & $100^{\circ}$ \\
\hline
\end{tabular}

C

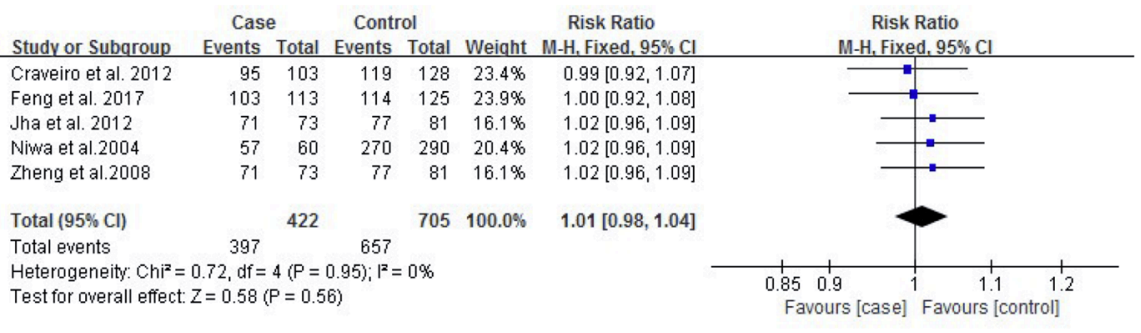

D

\begin{tabular}{|c|c|c|c|c|c|c|c|c|c|}
\hline \multirow[b]{2}{*}{ Study or Subqroup } & \multicolumn{2}{|c|}{ Case } & \multicolumn{2}{|c|}{ Control } & \multirow{2}{*}{\multicolumn{2}{|c|}{$\begin{array}{cc} & \text { Risk Ratio } \\
\text { Weight } & \text { M-H, Fixed, } 95 \% \mathrm{Cl}\end{array}$}} & \multirow{2}{*}{\multicolumn{3}{|c|}{$\begin{array}{c}\text { Risk Ratio } \\
\text { M-H, Fixed. 95\% Cl }\end{array}$}} \\
\hline & Events & Total & Events & Total & & & & ed, $95 \% \mathrm{C}$ & \\
\hline Craveiro et al. 2012 & 228 & 282 & 286 & 352 & $21.8 \%$ & $1.00[0.92,1.07]$ & & & \\
\hline Feng et al. 2017 & 273 & 360 & 283 & 360 & $24.3 \%$ & $0.96[0.89,1.04]$ & & & \\
\hline Jha et al. 2012 & 170 & 202 & 173 & 200 & $14.9 \%$ & $0.97[0.90,1.06]$ & & & \\
\hline Niwa et al. 2004 & 166 & 224 & 692 & 880 & $24.1 \%$ & $0.94[0.87,1.03]$ & & - & \\
\hline Zheng et al. 2008 & 170 & 202 & 173 & 200 & $14.9 \%$ & $0.97[0.90,1.06]$ & & & \\
\hline Total $(95 \% \mathrm{Cl})$ & & 1270 & & 1992 & $100.0 \%$ & $0.97[0.93,1.00]$ & & & \\
\hline Total events & 1007 & & 1607 & & & & & & \\
\hline $\begin{array}{l}\text { Heterogeneity: } \mathrm{Chi}^{\mathbf{z}} \\
\text { Test for overall effec }\end{array}$ & $\begin{array}{l}0.93, d f= \\
Z=1.71(f\end{array}$ & $\begin{array}{l}4(P= \\
P=0.0\end{array}$ & $\begin{array}{l}0.92) ; 1^{2}= \\
9)\end{array}$ & & & & 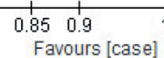 & $\begin{array}{l}1 \\
1\end{array}$ & $\begin{array}{ll}1 & 1 \\
1.1 & 1.2 \\
\text { is [control] }\end{array}$ \\
\hline
\end{tabular}

Figure 2: Meta-analysis of genetic polymorphism and cervical cancer. (A) Recessive model; (B) Dominant model; (C) Co-dominat model; (D) Allelic model.

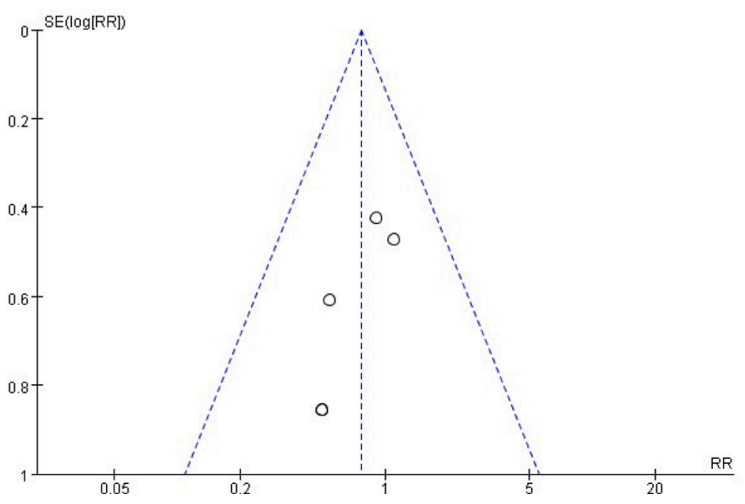

Figure 3: Publication bias analysis. 


\section{The inclusion and exclusion criteria of literatures}

All the included studies must meet to the following criteria: (1) independently published case-control or cohort studies on the relation between $P 73$ polymorphism and cervical cancer; (2) with comprehensive statistical indicators directly or indirectly: OR or RR (relative risk) values and 95\% CI (confidence interval); and (3) similar themes and methods, that is, case-control or cohort studies about the relation of the $P 73$ gene polymorphism and cervical cancer. The literatures were excluded if relevant data are not available or there is heterogeneity of gene polymorphism in the control population.

\section{Quality assessment and data extraction}

Two reviewers independently evaluated the research design, enrolled patients, observation results of the literature, and selected trials according to the above-mentioned inclusion criteria. Inconsistencies were resolved through discussion. We used the Cochrane Handbook 5.2 quality evaluation criteria to assess the methodological quality of included studies. To determine the quality of data by the quality of ultimately determined literature, the useless ones will be excluded, such as studies that have been reported repeatedly and those with poor quality or less information and have special selection of laboratory sample; relevant data were extracted from included literatures.

\section{Statistical analysis}

We performed the present meta-analysis utilized RevMan 5.2 software which provided by the Cochrane Collaboration. $Q$-test and $I^{2}$ test was used to examine the heterogeneity between each study. We used odds ratio (OR) for efficacy analysis statistics. In the present study, we selected the fixed effects model to merge the OR. Analysis of sensitivity includes the difference of point estimation and confidence intervals of the combined effects value of different models to observe whether it changes the result. To test the publication bias, we utilized the RevMan 5.2 statistical software to make the funnel plot. $P<0.05$ was considered as a significant difference.

\section{ACKNOWLEDGMENTS AND FUNDING}

None.

\section{CONFLICTS OF INTEREST}

We state that we have no conflicts to disclose.

\section{REFERENCES}

1. Dongol S, Tai Y, Shao Y, Jiang J, Kong B. A retrospective clinicopathological analysis of small-cell carcinoma of the uterine cervix. Mol Clin Oncol. 2014; 2:71-75.
2. Fernandez LM, Becker JA. Women's Select Health Issues in Underserved Populations. Prim Care. 2017; 44:47-55.

3. Senba M, Mori N. Mechanisms of virus immune evasion lead to development from chronic inflammation to cancer formation associated with human papillomavirus infection. Oncol Rev. 2012; 6:e17.

4. Kotulak A, Wronska A, Kobiela J, Godlewski J, Stanislawowski M, Wierzbicki P. Decreased expression of p73 in colorectal cancer. Folia Histochem Cytobiol. 2016; 54:166-170.

5. Teoh PJ, Bi C, Sintosebastian C, Tay LS, Fonseca R, Chng WJ. PRIMA-1 targets the vulnerability of multiple myeloma of deregulated protein homeostasis through the perturbation of ER stress via p73 demethylation. Oncotarget. 2016; 7:61806-61819. doi: 10.18632/ oncotarget.11241.

6. Guo H, Yang S, Xu L, Li D, Tang J, Wang S, Wei B, Liu Z. Association between the p73 gene G4C14-to-A4T14 single nucleotide polymorphism and risk of cervical cancer by high resolution melting and PCR with confronting two-pair primers in a Chinese population. Oncol Lett. 2016; 12:721-726.

7. Jha AK, Nikbakht M, Jain V, Sehgal A, Capalash N, Kaur J. Promoter hypermethylation of p73 and p53 genes in cervical cancer patients among north Indian population. Mol Biol Rep. 2012; 39:9145-57.

8. Craveiro R, Costa S, Pinto D, Salgado L, Carvalho L, Castro C, Bravo I, Lopes C, Silva I, Medeiros R. TP73 alterations in cervical carcinoma. Cancer Genet Cytogenet. 2004; 150:116-21.

9. Zheng L, Pan X, Yang A, Zheng X, Wang X, Zhou Q, Li X. Study of p73G4A polymorphism in HPV-associated cervical carcinoma in Uigur woman in Xinjiang. Chin J Mod Med. 2008; 18:2302-2306.

10. Craveiro R, Bravo I, Catarino R, Teixeira AL, Sousa H, Pereira D, Pereira H, Medeiros R. The role of p73 G4C14to-A4T14 polymorphism in the susceptibility to cervical cancer. DNA Cell Biol. 2012; 31:224-9.

11. Niwa Y, Hamajima N, Atsuta Y, Yamamoto K, Tamakoshi A, Saito T, Hirose K, Nakanishi T, Nawa A, Kuzuya K, Tajima K. Genetic polymorphisms of p73 G4C14-to-A4T14 at exon 2 and p53 Arg72Pro and the risk of cervical cancer in Japanese. Cancer Lett. 2004; 205:55-60.

12. Feng H, Sui L, Du M, Wang Q. Meta-analysis of TP73 polymorphism and cervical cancer. Genet Mol Res. 2017; 16. doi: $10.4238 /$ gmr16016571.

13. Yoon MK, Ha JH, Lee MS, Chi SW. Structure and apoptotic function of p73. BMB Rep. 2015; 48:81-90.

14. Jancalek R. The role of the TP73 gene and its transcripts in neuro-oncology. Br J Neurosurg. 2014; 28:598-605.

15. John K, Alla V, Meier C, Pützer BM. GRAMD4 mimics p53 and mediates the apoptotic function of $\mathrm{p} 73$ at mitochondria. Cell Death Differ. 2011; 18:874-86.

16. Lefkimmiatis K, Caratozzolo MF, Merlo P, D'Erchia AM, Navarro B, Levrero M, Sbisa' E, Tullo A. p73 and p63 sustain cellular growth by transcriptional activation of cell cycle progression genes. Cancer Res. 2009;69:8563-71. 